First publ. in : Nature Reviews : Molecular Cell Biology ; 2 (2001), 8. - S. 589-598

DOI : $10.1038 / 35085008$

\title{
FOUR DEATHS AND A FUNERAL: FROM CASPASES TO ALTERNATIVE MECHANISMS
}

\author{
Marcel Leist* and Marja Jäättelä ${ }^{\ddagger}$ \\ A single family of proteases, the caspases, has long been considered the pivotal executioner \\ of all programmed cell death. However, recent findings of evolutionarily conserved, caspase- \\ independent controlled death mechanisms have opened new perspectives on the biology of \\ cell demise, with particular implications for neurobiology, cancer research and immunological \\ processes.
}

CASPASES

Family of cysteine proteases that can be divided into inflammatory caspases, and pro-apoptotic caspases, which can be further grouped into initiator and effector caspases.

PHAGOCYTOSIS

Uptake of dying cells by macrophages or neighbouring cells. Recognition of 'eat-me' signals by specific receptors on the phagocytosing cell.

DEATH RECEPTORS

A family of cell-surface receptors that can mediate cell death upon ligand-induced trimerization.

${ }^{*} H$. Lundbeck $A / S$, Ottiliavej 9, DK-2500 Copenhagen-Valby, Denmark e-mail. male@lundbeck.dk ${ }^{\ddagger}$ Apoptosis Laboratory Danish Cancer Society, Strandboulevarden 49 DK-2100 Copenhagen,

Denmark. e-mail mhj@biobase.dk
Programmed cell death (PCD) is essential for the development and maintenance of multicellular organisms. Many eukaryotic cells that die and are removed in a programmed way undergo an astonishingly stereotypical series of biochem ical and morphological changes, the most defining features of which are the activation of CASPASES, chromatin condensation and the display of PHAGOCYTOSIS markers on the cell surface ${ }^{1-3}$. The underlying death process has been called apoptosis to delineate it clearly from other death programmes (BOX 1).

The unexpected ability of certain cells to survive the activation of pro-apoptotic caspases ${ }^{4-9}$ demonstrates a remarkable plasticity of the cellular death programme, and does not support the idea that caspases alone are sufficient for the induction of mammalian PCD. Furthermore, recent evidence indicates a diversification of the apoptosis programme in higher eukaryotes with respect to the necessity and role of caspases. Namely, apoptosis-like cell death can occur without the activation of effector caspases ${ }^{9-18}$, and signals emanating from the established key factors of apoptosis - including DEATH RECEPTORS and caspases themselves - may result in a non-apoptotic death ${ }^{19-21}$ (BOX 1).

Remarkably, modifications in the mode of death do not necessarily affect the efficient removal of dying cells $^{22,23}$. So, some of the alternative caspase-independent death pathways might have evolved to fulfil the same purpose as that proposed for classical apoptosis - that is, to guarantee a safe and non-inflammatory removal of corpses. We present here a differentiated view on PCD, based not on the activation of caspases, but rather on the morphology and fate of dying cells (BOX 1). The discussion of medically relevant fields, such as neurology and oncology, also takes into account the implications of the death mode for the surrounding tissue and the potential of caspase-independent PCD signalling mechanisms as therapeutic targets.

\section{Evolution of cell death principles}

The driving evolutionary pressures for the development of several cell-death programmes have been increasing in parallel with the increased complexity and life span of the organisms ${ }^{24}$. But when in evolution did the caspase-independent death mechanisms arise? Caspasecoding sequences are absent from the known genomes of many non-animal species ${ }^{24}$. Nevertheless, such organisms - including plants and several single-celled eukaryotes - undergo PCD under conditions of stress $^{25,26}$. For instance, in yeast, this apoptosis-like death is associated with DNA fragmentation, zEIOSIs, PHOSPHATIDYLSERINE EXPOSURE and chromatin condensation $^{25}$, and can be selectively triggered or blocked by Bax-like or CED-9-related genes, respectively. Furthermore, programmed PARAPTOSIs-like death is well characterized in caspase-deficient slime moulds ${ }^{27}$.

The introduction of the caspases, and especially of the mitochondrial CED-9/Bcl-2-related death switch$\mathrm{es}^{24,26}$, might represent a decisive refinement of the old caspase-independent death programmes. The relative importance of different death mechanisms seems to 


\section{Box 1 Four patterns of death: from apoptosis to necrosis}

Apoptosis is defined by stereotypic morphological changes, especially evident in the nucleus where the chromatin condenses to compact and apparently simple geometric (globular, crescent-shaped) figures ${ }^{1}$. Other typical features include phosphatidylserine exposure, cytoplasmic shrinkage, zeiosis and the formation of apoptotic bodies (with nuclear fragments) (BOX 2). In its most classic form, apoptosis is observed almost exclusively when caspases, in particular caspase- 3 , are activated. When death can be blocked by inhibition of any signal or activity (for example, caspases) within the target cell, then the simplest condition for programmed cell death (PCD) is met. Apoptotic morphology results from one of the most elaborate forms of PCD, and it may be viewed as a far end of a continuum of death modes, with varying contributions of the cellular machinery.

Apoptosis-like PCD is used here to describe forms of PCD with chromatin condensation that is less compact/complete than in apoptosis (geometrically more complex and lumpier shapes), and with the display of phagocytosis-recognition molecules before lysis of the plasma membrane. Any degree and combination of other apoptotic features can be found. Most published forms of 'caspase-independent apoptosis' fall into this class. Notably, some classic 'caspase-dependent apoptosis' models, such as tumour-necrosis-factor-induced death of MCF-7 cells, also have this morphology. For comparative examples see BOX2.

Necrosis-like PCD is used here to define PCD in the absence of chromatin condensation, or at best with chromatin clustering to speckles ${ }^{19,20,33,34,104}$. Varying degrees of other apoptosis-like features - including externalization of phosphatidylserine - might occur before the lysis ${ }^{33,34}$. Necrotic PCD usually involves specialized caspase-independent signalling pathways. However, caspase- 8 might be activated $^{21}$ and caspase-1-driven necrosis has also been observed ${ }^{112}$. A subgroup of necrotic PCD models are often classified as 'aborted apoptosis'; that is, a standard apoptosis programme is initiated, then blocked at the level of caspase activation and finally terminated by alternative, caspase-independent routes ${ }^{30}$.

Accidental necrosis/cell lysis is the conceptual counterpart to PCD, as it is prevented only by removal of the stimulus. It occurs after exposure to high concentrations of detergents, oxidants, ionophores or high intensities of pathologic insult ${ }^{30}$. Necrosis is often associated with cellular OEDEMA (organelle swelling) and devoid of zeiosis (see movies 3 and 4 online). The necrotic tissue morphology is, in large part, due to postmortem events (occurring after lysis of the plasma membrane) ${ }^{30}$.

\section{OEDEMA}

Water accumulation and swelling within a tissue, cell or organelle.

\section{ZEIOSIS}

Dynamic plasma membrane blebbing of a dying cell analogous to the bubbling of fermenting yeast.

PHOSPHATIDYLSERINE EXPOSURE

Translocation of phosphatidylserine, which is confined to the inner leaflet of the plasma membrane in healthy cells, to the outside of the plasma membrane where it is recognized by a specific receptor on macrophages.

PARAPTOSIS

A form of programmed cell death without prominent chromatin condensation and mainly characterized by cytoplasmic vacuolization have been optimized subsequently in various ways. One form of extreme specialization is exemplified by somatic cell death in the nematode Caenorhabditis elegans, which sits on a branch of the phylogenetic tree that separated early from the branch leading to mammalian development. Accordingly, the requirements for PCD in C. elegans are adapted to its specific needs and have diverged widely from those of mammals ${ }^{24}$. As the environmental pressure to provide a flexible death response is very low in this short-lived organism, it has been enough to optimize only one stereotyped caspasedependent apoptosis programme. In contrast to mammals, control by mitochondrial proteins might not be required, and most degradative enzymes are supplied by the phagocytosing cell rather than by the dying cell itself $^{2,3}$.Apoptosis in C. elegans is often cell autonomous - that is, it is neither signalled nor controlled from outside and the entire system of death receptors seems to be absent. In accordance with this minimalist programme, somatic PCD is not essential for the survival or the development of $C$. elegans ${ }^{28}$. Rudimentary remainders of alternative apoptotic programmes are, however, still found in the MALE LINKER CELL, in which
PCD that might be independent of CED-3 is triggered from outside ${ }^{28}$.

The mammalian system of death programmes could represent an opposite form of evolutionary direction in which, apart from the many caspases, other cysteine proteases and mitochondrial factors have taken additional roles during development and life ${ }^{3,29}$. The essential nature of some factors (knockout lethality ${ }^{18,29}$ ) combined with the redundancy of others (difficulty with interpretation of knockouts ${ }^{29}$ ) has made the study of their specific role in PCD technically challenging. In addition, it has remained unclear which mechanisms are essential for commitment to death and which ones only determine the phenotypic outcome $\mathrm{e}^{30}$.

\section{PCD can take many forms}

If one keeps to the strict morphological criteria of apoptosis - including the geometrical shape of chromatin after its condensation (BOX 2) - caspases seem to be indispensable for apoptosis (BOX 1). However, there are many forms of 'apoptosis-like PCD', in which the chromatin condenses into less geometric shapes and phagocytosis markers on the plasma membrane are displayed before cell lysis. An array of well-characterized cell death models that occur in the absence of caspase activation falls into this catego$\mathrm{ry}^{9-17,31}$ (BOX 2). Furthermore, an analysis of cell membrane dynamics in different death models has revealed that an important hallmark of apoptosis, zeiosis, can occur independently of caspase activation $^{9,32}$ (see movies 1 and 2 online). PCD can also occur in the absence of chromatin condensation ${ }^{20,33,34}$. Such necrosis-like PCD is the result of active cellular processes that can be intercepted by, for instance, oxygen-radical scavengers ${ }^{20,35}$, inhibition of poly(ADP) ribose polymerase (PARP) ${ }^{36}$ or mutations in intracellular signalling molecules ${ }^{34}$. Further caspase-independent modes of PCD include autophagy - characterized by the formation of large, lysosome-derived cytosolic vacuoles ${ }^{17,37,38}$ - and DARKCELL DEATH in specialized cells such as chondrocytes ${ }^{39}$ or neurons ${ }^{40}$.

Contrary to earlier expectations, the inhibition of caspase activation does not necessarily protect against cell death stimuli. Instead it might reveal, or even enhance, underlying caspase-independent death programmes. These programmes might resemble apoptosis-like PCD ${ }^{9,41-43}$, autophagy ${ }^{44}$ or even necrosis ${ }^{19,20,32,45-48}$. In many experimental apoptosis models, including those triggered by death receptors ${ }^{20,34,42,46,48}$, cancer drugs $^{49}$, growth-factor deprivation ${ }^{44}$, STAUROSPORINE ${ }^{41}$, anti-CD2 ${ }^{41}$, oncogenes ${ }^{32}$, colCHICINE ${ }^{43}$ or the expression of Bax-related proteins ${ }^{32,45}$, the existence of back-up death pathways has been uncovered after inhibition of caspase activity by pharmaceutical PAN-CASPASE INHIBITORS. However, several lines of evidence also support the relevance of such 'second-line' mechanisms for normal physiology and pathology. For example, caspase pathways can be inactivated not only by pharmacological inhibitors, but also by other factors such as mutations ${ }^{47}$, energy depletion ${ }^{19}$, nitrative/oxidative stress ${ }^{21}$, other proteases that are activated simultaneously ${ }^{50,51}$, members of 


\section{Box 2 Nuclear alterations in different forms of proarammed cell death}

The use of chromatin condensation as a criterion to distinguish apoptosis from apoptosis-like PCD has been inconsistent in the scientific literature, and the potential for overlapping definitions and errors is large. The following examples of classical apoptosis $(\mathrm{c}, \mathrm{e})$ and apoptosis-like PCD (b,d,f,g-i) might provide a general guideline. Examples of control chromatin (a), and caspase-independent chromatin margination triggered directly by microinjection of AIF (b) (reproduced with permission from REF. $78 \odot$ (1999) Macmillan Magazines Ltd). Caspasedependent strong chromatin compaction (c) versus caspaseindependent, AIF-driven lumpy chromatin condensation (d) in PCD of mouse embryonic stem cells (reproduced with permission from REF. $18 \odot$ (2001) Macmillan Magazines Ltd). (e) Caspase-dependent chromatin compaction to crescent shaped masses at the nuclear periphery and chromatin fragmentation to two compact spheres (f) or caspase-independent lumpy chromatin condensation without nuclear fragmentation in colchicine-induced neuronal cell death (reproduced with permission from REF. $43 \odot$ (2001) The John Hopkins University Press). Incomplete, lumpy chromatin condensation (compare with b,d) in caspaseindependent apoptosis-like PCD triggered by Hsp70 depletion ${ }^{16}$ (g) or the active form of vitamin $\mathrm{D}^{15}$ (i), and in caspase-dependent TNF-induced apoptosis-like PCD (h) in caspase-3 deficient MCF-7 cells. (L. Bastholm, F. Flling, I. Stenfeldt Mathiasen and J. Nylandsted are acknowledged for providing the unpublished panels $\mathrm{g}-\mathrm{i}$.)

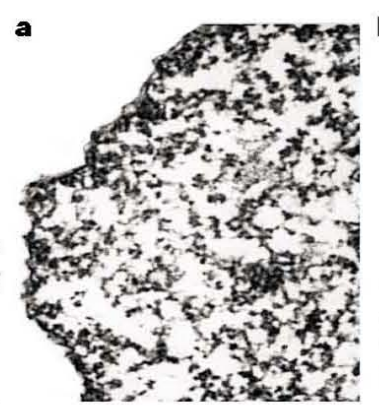

\section{c.}

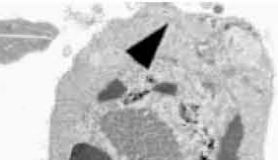

\begin{abstract}
$\mathbf{d}^{*}$
\end{abstract}
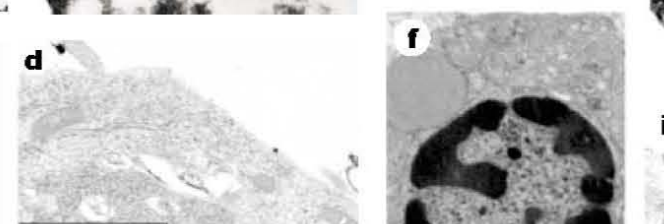

i
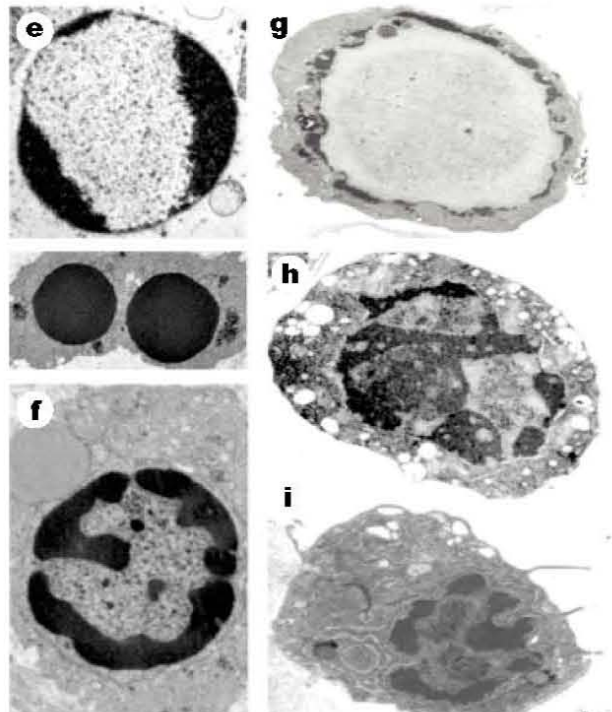

MALE LINKER CELL

The linker cell is a male-specific cell at the tip of the developing gonad. It 'guides' growth of the male gonad from the midbody region towards the tail. When the gonad has reached the tail late in larval development, the linker cell is 'murdered' by one of two neighbouring clls.

DARK CELL DEATH

Slow neuronal death observed, for example, during Huntington's disease. Characterized by strong cytoplasmic condensation, chromatin clumping, ruffling of the cell membrane, but no blebbing of the nucleus or plasma membrane.

PARP

Poly(ADP)-ribose polymerase A nuclear enzy me activated by DNA damage and reducing cellular ATP levels when overactivated.

STAUROSPORINE

Plant-derived cytotoxin known to trigger mitochondriadependent apoptosis in most cell types. Model apoptosis inducer. 
Table 1 | Death by more than a thousand cuts

\begin{tabular}{|c|c|c|c|c|}
\hline Protease activation & Protease & Antiprotease & Antiprotease inactivation & Comments \\
\hline $\begin{array}{l}\text { Cysteine proteases } \\
\text { Several proteolytic } \\
\text { steps; autoproteolysis/ } \\
\text { proteolysis by other } \\
\text { proteases (caspases, } \\
\text { granzyme B, cathepsins). }\end{array}$ & Caspase & $\mathrm{AP}$ & $\begin{array}{l}\text { Proteolysis of IAP proteins } \\
\text { (for example, caspases); } \\
\text { displacement (DIABLO). }\end{array}$ & $\begin{array}{l}\text { At least } 14 \text { isoenzymes in } \\
\text { different cellular organelles; } \\
\text { cleavage at defined motifs } \\
\text { (Asp at cleavage site P1). }\end{array}$ \\
\hline $\begin{array}{l}\text { Autoproteolysis }(\mathrm{pH} \\
\text { dependent); other } \\
\text { lysosomal proteases. }\end{array}$ & $\begin{array}{l}\text { Cys- } \\
\text { cathepsins }\end{array}$ & Cystatins & $\begin{array}{l}\text { Proteolysis (for example, } \\
\text { cathepsin D). Some cystatins } \\
\text { are cytosolic (A,B) or } \\
\text { extracellular (C), indicating } \\
\text { many roles of cathepsins } \\
\text { in these compartments. }\end{array}$ & $\begin{array}{l}\text { Large protease family } \\
\text { usually confined to } \\
\text { lysosomes. Potential } \\
\text { for change of substrate } \\
\text { specificity and localization } \\
\text { (cytosol, extracellular). }\end{array}$ \\
\hline $\begin{array}{l}\text { Many proteolytic steps; } \\
\text { autoproteolysis ( } \mathrm{Ca}^{2+} \\
\text { dependent); membrane } \\
\text { translocation. }\end{array}$ & Calpains & Calpastatin & $\begin{array}{l}\text { Proteolysis (for example, } \\
\text { caspases, calpains). }\end{array}$ & $\begin{array}{l}\text { Small family of proteases } \\
\text { with important role in } \\
\text { cytosolic/nuclear proteolytic } \\
\text { signalling. }\end{array}$ \\
\hline $\begin{array}{l}\text { Other proteases } \\
\text { Proteolysis, for example, } \\
\text { by caspases; serine } \\
\text { proteases (SerProt) } \\
\text { are no longer inhibited } \\
\text { upon cleavage of LEI. }\end{array}$ & SerProt & $\begin{array}{l}\text { Serpins } \\
\text { (for example, } \\
\text { LEI) }\end{array}$ & $\begin{array}{l}\text { Proteolysis (for example, } \\
\text { elastase) or oxidation; } \\
\text { protease inhibitor LEI is } \\
\text { transformed into L-DNase II. }\end{array}$ & $\begin{array}{l}\text { AP24 and other non- } \\
\text { characterized serine proteases } \\
\text { act as essential execution } \\
\text { proteases together with, or } \\
\text { independent of, caspases. }\end{array}$ \\
\hline $\begin{array}{l}\text { This specific class of } \\
\text { serine proteases is } \\
\text { activated by proteolysis } \\
\text { (dipeptidylpeptidase I). }\end{array}$ & Granzymes & Serpins & Proteolysis & $\begin{array}{l}\text { Many proteolytic roles in the } \\
\text { the activation of caspases or } \\
\text { Bid; direct induction of PCD } \\
\text { and cleavage of nuclear lamins; } \\
\text { found in the granules of T cells. }\end{array}$ \\
\hline $\begin{array}{l}\text { Ubiquitylation of } \\
\text { substrates } \\
\text { (ATP dependent). }\end{array}$ & Proteasome & & & $\begin{array}{l}\text { Continuous turnover of } \\
\text { short-lived proteins. Different } \\
\text { proteolytic activities. Regulation } \\
\text { of steady state of factors } \\
\text { relevant for PCD. }\end{array}$ \\
\hline $\begin{array}{l}\text { Proteolysis } \\
\text { Ceramide } \\
\text { p53-dependent } \\
\text { transcription. }\end{array}$ & Cathepsin D & & & $\begin{array}{l}\text { Aspartyl protease; might } \\
\text { translocate from lysosomes to } \\
\text { cytosol or extracellular space } \\
\text { and trigger apoptosis. }\end{array}$ \\
\hline
\end{tabular}

Information taken from REFS 4,9,64,54,114. IAP, inhibitor of apoptosis: $\mathrm{PCD}$, programmed cell death.

features of apoptosis: for example, cleavage of the inhibitor of caspase-activated DNase (ICAD) leads to chromatin changes; cleavage of lamins results in nuclear shrinkage; cleavage of cytoskeletal proteins leads to cytosolic reorganization; and cleavage of $\mathrm{p} 21$ activated kinase- 2 or Rho-activated serine/threonine kinase leads to blebbing ${ }^{2,59}$. So what brings about the apoptotic features observed in cells that die in a caspase-independent manner?

The first guess is, naturally, other proteases (for instance, cathepsins, calpains, serine proteases and the proteasome complex; TABLE 1). Indeed, data based on activity measurements, protease inhibitors and/or genetic deletion support their roles as essential cofactors either upstream or downstream of caspases in several cell death models $s^{4,9,10,60-69}$. Furthermore, many non-caspase proteases can cleave at least some of the classic caspase substrates, indicating that they might also mimic the cellular effects of caspases ${ }^{62,64,65,68}$. Accordingly, evidence is emerging for the ability of other proteases to induce apoptosis-like PCD in the absence of caspase activation. Examples include the roles of cathepsins D and $B$ in camptothecin-induced death of liver cancer cells $^{10}$; of cathepsin $\mathrm{B}$ in fibrosarcoma cells treated with $\mathrm{TNF}^{9}$; of the proteasome in colchicine-treated neurons $^{43}$; and of calpains in vitamin-D-treated breast- cancer cells (M.J., unpublished observation). But more work is needed to define the role of the individual proteases in the complex process of PCD. Genetic approaches need to be combined with meticulous pharmacological titration of inhibitors $s^{9}$, as it turns out that pan-caspase inhibitors, as well as many active-site inhibitors of other proteases, are highly unspecific at the concentrations widely used to test their role in $\mathrm{PCD}^{9,62,64,70}$

Death receptors as triggers. The best-studied members of the death-receptor family are TNF receptor-1 (TNFR1) and Fas (also known as CD95 or Apo-1). Whereas it has long been known that TNF-induced death can take the shape of either apoptosis or necrosis ${ }^{71}$, the ability of Fas to induce necrosis-like PCD has been described only recently ${ }^{19-21,34,72}$. Interestingly, in activated primary Tlymphocytes, this caspase-independent necrosis-like PCD seems, at least in some cases, to be the dominant mode of death ${ }^{34}$. This might explain why inhibition of caspase activity in mouse Tlymphocytes in vivo does not induce the lymphadenopathy and/or autoimmune disease usually manifested in mice with inactivating mutations in Fas or Fas ligand ${ }^{53}$.

The demonstration that caspase- 8 is recruited to ligand-activated receptors through a receptor-associated 
a Ligand-actirated Fas

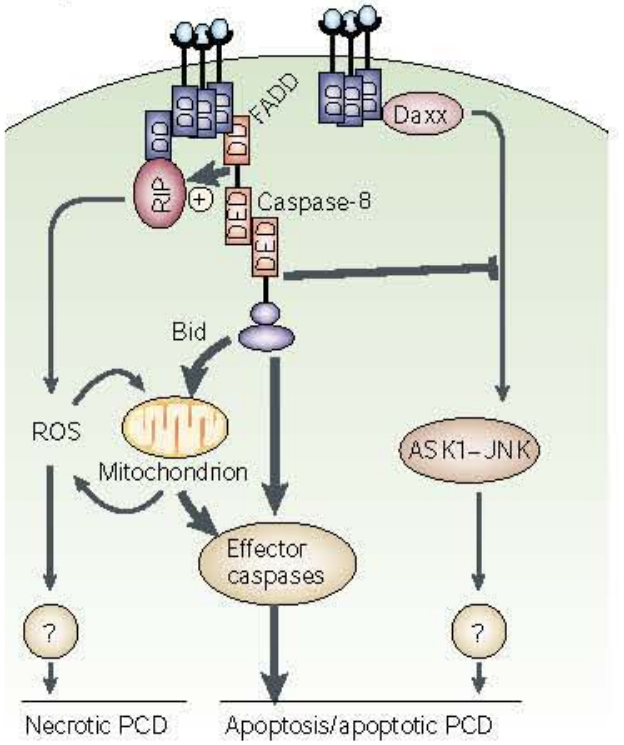

b Ligand-activated TNFR1

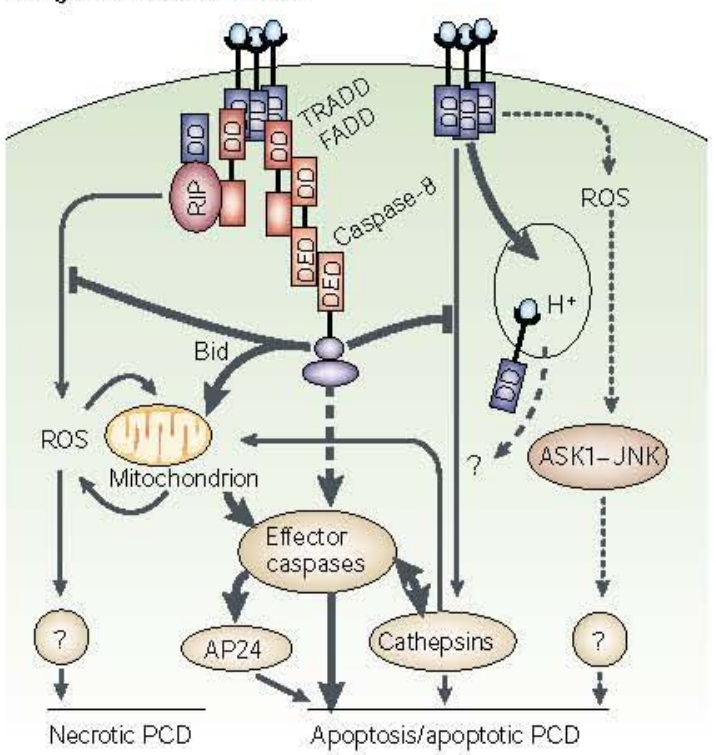

Figure 1 | Multiple death pathways triggered by death receptors. Death-receptor signalling is initiated by ligand-induced receptor trimerization. a Receptor death domains (DD) of Fas then recruit FADD. RIP and/or Daxx to the receptor complex. Caspase- 8 is activated after recruitment to FADD through interactions between the death effector domains (DED) in the two proteins, and triggers effector caspases either directly or through a Bid-mediated mitochondrial pathway ${ }^{3}$ (thick arrows). RIP initiates a caspase-independent (thin arrows) necrotic pathway me diated by the formation of reactive oxygen species (ROS) ${ }^{34}$. Daxx activates the apoptosis-stimulating kinase 1/Jun amino-terminal kinase (ASK1-JNK) pathway, leading to caspaseindependent apoptosis ${ }^{73.74,77}, \mathrm{~b}$ | Tumour necrosis factor receptor-1 (TNFR1) signalling differs from that of Fas in the following steps. First, binding of FADD and RIP to the receptor complex requires the adaptor protein TRADD. Second, binding of Daxx to TNFR1 has not been shown and the ASK1-JNK pathway is activated by ROS ${ }^{73.75}$ (dotted line, caspase involvement unclear). Third, the RIP-mediated necrotic pathway is inhibited ${ }^{34}$ by caspase-8. Fourth. TNFR1 can initiate a caspase-independent direct cathepsin-B-mediated pathway ${ }^{9}$. Fifth, cathepsin B can enhance the mitochondrial death pathway ${ }^{61}$. Last, the final execution of the death - that is, phosphatidylserine exposure, chromatin condensation and loss of viability - is brought about by effector caspases, the serine protease AP24 or cathepsin B in a cell-type-specific manner $r^{3.4961}$. PCD, programmed cell death.

DEATH DOMAIN A conserved sequence motif first identified in the intracellular parts of death receptors. Later reoognized as the key motif for association of the receptors with cytosolic death-domain-containing proteins (FADD, TRADD, RIP) and the induction of cell death

REACTIVE OXYGEN SPECES (ROS). Collective term comprising intracellularly formed classic oxygen radicals and peroxides.
DEATH DOMANN protein FADD led to the first molecular models of death-receptor-induced apoptosis ${ }^{3}$ (FIG. 1). Later, Fas was also suggested to induce an alternative apoptosis programme, mediated by recruitment of the nuclear Daxx protein to the receptor, and the subsequent activation of apoptosis-stimulating kinase 1 (ASK1) and Jun amino-terminal kinases (JNK1/2) ${ }^{7.74}$. However, subsequent data from studies using primary fibroblasts derived from mice deficient for $A s k I$ (REF. 75) or $J n k 1 / 2$ (REF. 76) cast doubt on the relevance of this kinase pathway. This controversy might be resolved by a report indicating that, in mary cells, the Daxx-ASK1-JNK pathway, which is not inhibited by pan-caspase inhibitors, might be either overruled by a more rapid induction of the caspase pathway or blocked by expression of the small heatshock protein Hsp27 (REF. 77). ASK1 has also been found to be essential for TNF-triggered apoptosis of primary fibroblasts, but its activation by TNF seems to require REACTIVE OXYCEN SPECES (ROS) ${ }^{75}$ instead of Daxx ${ }^{73}$. It remains to be studied whether the TNFR1-ROS-ASK1 pathway is caspase independent. As noted above, TNF can induce a cathepsin-B-mediated apoptosis-like programme, even in the absence of caspase activity ${ }^{9.42}$.

The molecular mechanisms underlying the necrosislike PCD that can be induced by death receptors have also been worked out recently. The necrotic programmes induced by death receptors are dependent on the kinase activity of the receptor-interacting protein $(\mathrm{RIP})^{34}$ and the formation of ROS ${ }^{20,34,48}$. Whereas the function of FADD as a general and essential caspase- 8 recruiter in death-receptor-induced apoptosis is well established ${ }^{3}$, its role in the necrotic pathway is more complex. Although FADD is indispensable for Fasinduced necrosis-like PCD ${ }^{34}$, it blocks TNFR1-induced necrosis, probably ${ }^{34,46}$ by activating caspase- 8 . So, the concentration of FADD might be one of the switches between the apoptotic and necrotic pathways triggered by TNF.

The picture described above indicates a complexity of death-receptor-induced apoptotic and necrotic signalling networks that far exceeds that of the simple linear pathway originally indicated by the discovery of the receptortriggered caspase cascade (FIG. 1).

Mitochondria as triggers. Many models of $\mathrm{PCD}$ involve some form of mitochondrial control, and it is useful to consider the signalling phases upstream and downstream of these organelles separately (FIG. 2). The proapoptotic $\mathrm{Bcl}$-2-related proteins - such as $\mathrm{Bax}, \mathrm{Bak}$, Bid and Bim - have a dominant role at the mitochondrial stage of PCD signalling 2.3 . These proteins translocate to the mitochondria, or change their conformation and interaction partners on the mitochondria, in response to various death stimuli. The regulatory coun- 


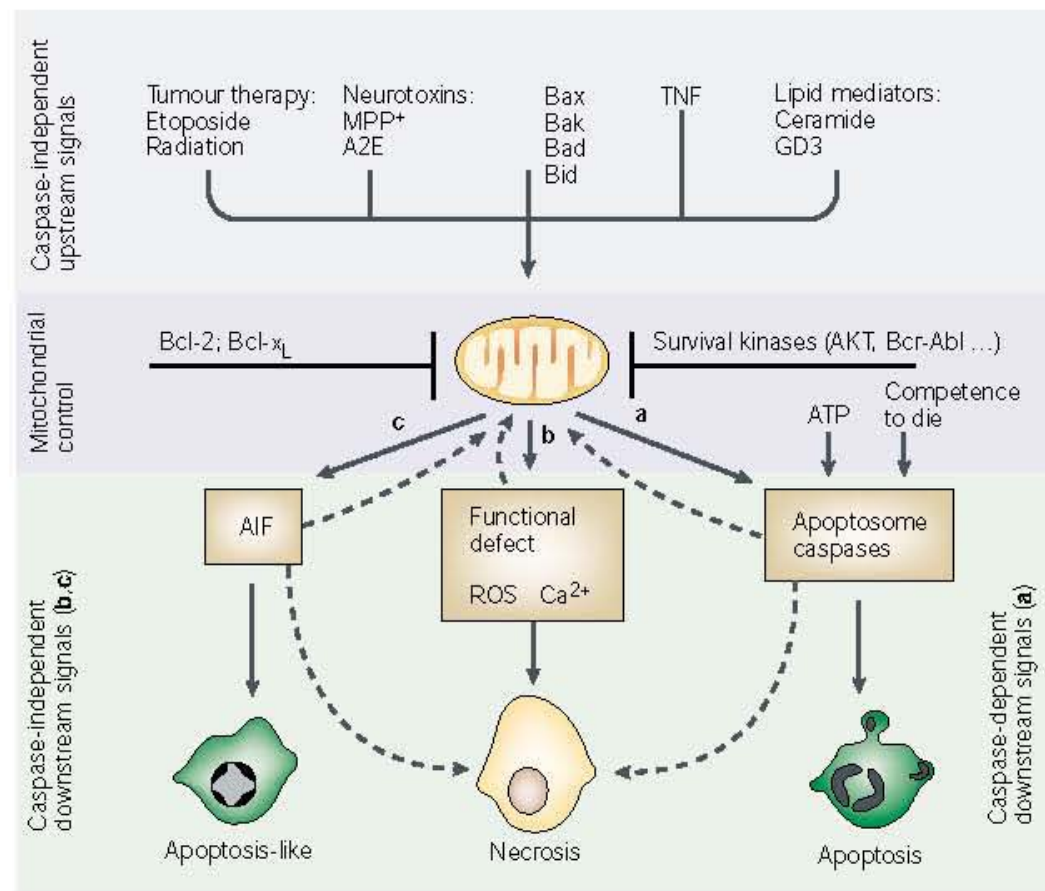

Figure 2 | Mitochondrial roles in caspase-independent PCD. Death triggers upstream of mitochondria usually do not require caspases. They include various chemotherapeutics, neurotoxins related to 1-methyl-4-phenylpyridinium (MPP) or the retinal cytotoxic pigment $\mathrm{A} 2 \mathrm{E}$, and lipid mediators such as ceramide or the disialoganglioside $\mathrm{GD} 3^{30,49,79}$. Most signals can be blocked by anti-apoptotic Bcl-2 family members or survival kinases that act on this level $\left.\right|^{3}$. Three fundamentally different and initially independent signals emanate from mitochondria. a |Cytochrome $c$, which leads to caspase activation in the apoptosome and thus triggers classical apoptosis ${ }^{23} \cdot \mathbf{b}$ | Reactive oxygen species (ROS) and $\mathrm{Ca}^{2+}$, which induce necrotic $P C D^{30.58}, \mathrm{c} \mid$ The apoptosis inhibitory factor (AIF), which is released from mitochondria and triggers apoptotic-like death associated with chromatin condensation and margination. but not advanced chromatin compaction and nuclear fragmentation ${ }^{78}$. All three processes might feed back to mitochondria, affecting their function and structure, and therefore trigger one another ${ }^{3.58 .78}$. Lack of essential cofactors for processes $\mathbf{a}$ and $\mathrm{c}$ will convert them to necrosis ${ }^{30}$. TNF, tumour necrosis factor.

\section{APOPTOSOME}

Multiprotein complex containing cytochrome $c$, Apaf1 and procaspase- 9 . Catalyses ATP-dependent auto-activation of caspases by induced proximity. Key regulatory step of developmental apoptosis.

$\mathrm{AIF}$

Apoptosis-inducing factor, a flavoprotein normally located in the mitochondrial intermembrane space. It is released during apoptosis and is involved in nuclear changes and death induction.

\section{ONCOPROTEINS}

Oncoproteins are encoded by oncogenes and their increased activity or expression promotes tum or igenesis either by inducing prolferation or by inhibiting cell death. terparts at this level include the anti-apoptotic members of the same family (for example, $\mathrm{Bcl}-2$ and $\mathrm{Bcl}-\mathrm{x}_{\mathrm{L}}$ ). Eventually, the ratio of death and survival signals sensed by the $\mathrm{Bcl}-2$-family proteins determines whether the cell will live or $\mathrm{di}^{23.30}$

Three death pathways are triggered downstream of mitochondrial changes (FIG. 2). The caspase pathway leading to classical apoptosis ${ }^{3.58}$ is initiated by the release of cytochrome $c$ from the mitochondrial intermembrane space. Together with other essential factors (such as ATP), it triggers assembly of the APOPTOSOME complex, which forms the template for efficient caspase processing. As a further safeguard mechanism, caspase-inhibitory factors (IAPs) have to be removed by additional proteins (DIABLO/Smac) that are released from mitochondria before the execution caspases can become fully active and produce the typically apoptotic morphology ${ }^{23}$

The second mitochondrial death pathway leads to necrotic $P C D$, without necessarily activating caspases. $A$ prominent example is TNF-induced necrosis-like PCD, mediated by mitochondria-derived $\mathrm{ROS}^{35}$. Intracellular control of this pathway is indicated by its susceptibility to attenuation by antioxidants ${ }^{2.35}$.
The third distinct pathway from mitochondria is the release of the apoptosis-inducing factor (AIF) from the intermembrane space ${ }^{78}$. Recent genetic evidence indicates that this factor controls PCD during early development - that is, all the hallmarks of early morphogenetic death, including cytochrome $c$ release, are prevented by deletion of $\mathrm{AIF}^{18}$. AIF induces caspase-independent formation of large $(50 \mathrm{~kb})$ chromatin fragments, whereas oligonucleosomal DNA fragments are generated only when caspase-activated DNase (CAD) is activated ${ }^{3.78}$. This biochemical difference is reflected by slight morphological differences in the shape of the condensed chromatin (FIG. 2, BOX 2).

Often, more than one of these three pathways seem to be activated simultaneously 6.58 .78 .79 . The cell fate (and death mechanism) is then determined by the relative speed of each process in a given model system and by the antagonists of the individual pathways that are differentially expressed in different cell types. However, the observation that $\mathrm{AIF}$, cytochrome $\mathrm{c}$ and $\mathrm{ROS} / \mathrm{Ca}^{2+}$ are released together in a given model does not necessarily imply that all pathways are concurrently triggered by mitochondria. Rather, AIF, caspases and ROS can feed back on mi tochondria, causing enough structural and functional damage to trigger the release of other death factors, independent of the upstream signals 3.30 .58 .78 ,

Defects in any step of the cytochrome cor AIF pathways will result in a switch from apoptosis to cell death with a necrotic morphology 19.32 .80 . This cell death would still fulfil the criteria of PCD, as it is blocked by the antiapoptotic oncogenes $\mathrm{Bcl}-2$ or $\mathrm{Bcr}-\mathrm{Ab} \mathrm{l}^{1980}$, or by the deletion of pro-apoptotic $\mathrm{Bax}^{81}$. Also, caspase inhibition changes the mode of death, but not its extent, once the signal has arrived at mitochondria ${ }^{19.30 .32,45,49.80-82}$. So it seems that in many models of cell death the master controllers of PCD operate at the mitochondrial level, whereas the decision on the shape of death is taken on the level of caspase activation ${ }^{30}$.

There are, however, certain cases in which expression of $\mathrm{Bcl}-2$ is not protective and in which mitochond ria might not have a regulatory role ${ }^{16.17 .38,83.84}$. Although alternative control mechanisms are not well characterized, emerging candidates include different chaperone systems, such as heat-shock proteins ${ }^{6.16 .77}$ or ORP150 (REF.85). Organelles that have not received much attention recently, such as the endoplasmic reticulum $\mathrm{m}^{58}$ and lysosomes ${ }^{65}$, might also have an essential role in the control of death.

The mechanism of cell death is not merely of academic interest - its importance stretches beyond the individual cell affected, as it might affect tissue reorganization and regeneration in the nervous system as well as immunological reactions in tumours. Characterization of the new death pathways throws light on diseases associated with dysregulated cell death, with possible implications for the classification and therapy of cancers and neurodegenerative disease.

\section{Complex control of tumour cell death}

Paradoxically, the cell proliferation induced by enhanced activity of oncoproteIns (such as Myc, E1A, E2F and 


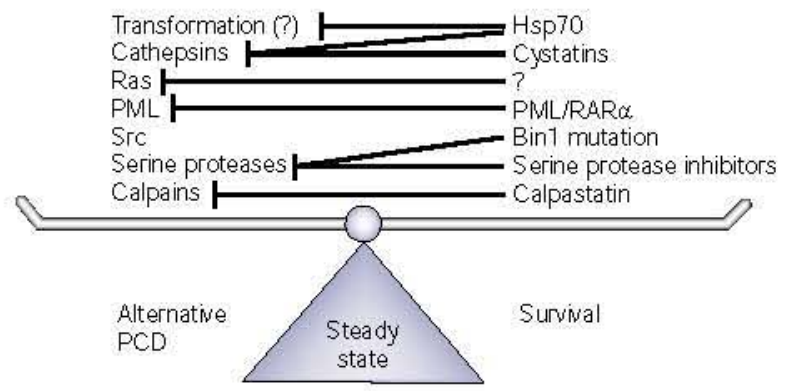

b

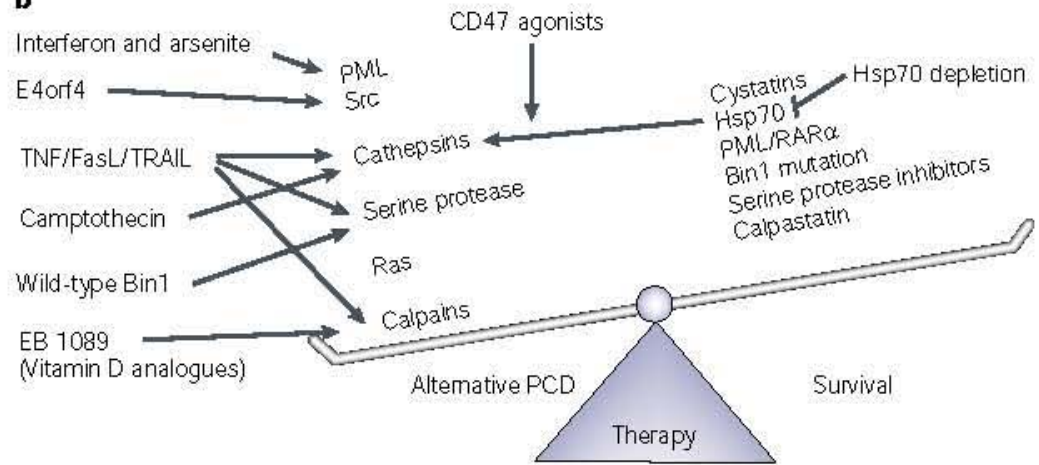

Figure $3 \mid$ Alternative death pathways as regulators of tumour cell survival and as putative targets for cancer therapy. a| Transformation is associated with upregulation of proteins that sensitize cells to caspase-independent programmed cell de ath (PCD) ${ }^{38.88 .90}$. As a counterweight, death-promoting proteins are inactivated or expression of survival proteins is enhanced $\mathrm{d}^{17.52 .65 .92}$. Analogous changes in prote ins that regulate caspase-dependent apoptosis have also been shown in cancer ${ }^{52.86} . \mathbf{b} /$ Strategies of cancer therapy aimed at facilitating alternative de ath pathways ${ }^{9-11.15-17.33 .88 .92}$. Hsp, heat-shock protein; PML, promyelocytic leukaemia; TNF, tumour necrosis factor; TRAIL, TNF-related apoptosis-inducing ligand; $R A R \alpha$, retinoic acid receptor- $\alpha$.

PTEN

A tumour-suppressor protein with phosphatase activity specific for inositol phospholipids. Negative regulator of protein kinase $B$ (Akt) pathway in cells.
CDC25) or inactivation of tumour-suppressor proteins (retinoblastoma protein, for example) is often associated with caspase activation and accelerated apoptosis ${ }^{86}$. The coupling of cell division to cell death has therefore been suggested to act as a barrier that must be circumvented for cancer to occur ${ }^{5286}$. Indeed, high expression of antiapoptotic proteins (Bcl-2, Bcl- $x_{L}$, survivin, $\mathrm{Bcr}-\mathrm{Abl}$ ) and/or inactivation of pro-apoptotic tumour-suppressor proteins ( $\mathrm{p} 53, \mathrm{p} 19^{\text {arf }}$,PTEN) controlling caspase-dependent apoptosis pathways are often seen in human tumours ${ }^{5286}$.

Alternative death pathways in cancer. Despite showing severe defects in classic apoptosis pathways, cancer cells have not lost the ability to commit suicide. On the contrary, spontaneous apoptosis is common in aggressive tumours, and most of them respond to some ther$a p y^{87}$. One explanation might be that the different strategies used by cancer cells to escape apoptosis are not enough to counteract the lethal signals coupled to transformation. Alternatively, defects in the signalling pathways that lead to caspase activation might allow caspase-independent death pathways to take a dominant role in tumour cell death.

The alternative death pathways might be enhanced by transformation (FIG. 3). For example, oncogenic Ras can induce caspase- and Bcl-2-independent autophagic death ${ }^{14}$, and tumour-associated Src-family kinases are involved in caspase-independent cytoplasmic execution of apoptotic programmes induced by adenovirus protein E4orf4 (REF. 88). Furthermore, a transformationassociated caspase-, p53- and Bcl-2-independent apoptosis-like death programme can be activated in tumour cell lines of different origins by depletion of a $70-k D a$ heat-shock protein $(\mathrm{Hsp} 70)^{16,89}$. This death is preceded by translocation of active cysteine cathepsins from lysosomes to cytosol, and inhibitors of their activity partially protect against death (M.J., unpublished observation). Interestingly, cysteine cathepsins, as well as other non-caspase proteases, are highly expressed in aggressive tumours ${ }^{90}$. So expression of protease inhibitors might increase a cancer cell's chances of survival by impairing alternative death routes ${ }^{9.65 .91}$.

Alternative death pathways can also function at an initial step of tumorigenesis to limit tumour formation. Bin1, a tumour-suppressor protein that is often missing or functionally inactivated in human cancer, can activate a caspase-independent apoptosis-like death process that is blocked by a serine protease inhibitor or simian virus large $T$ antigen, but not by overexpression of $\mathrm{Bcl}-2$ or inactivation of $\mathrm{p} 53$ (REF. 17 ). Similarly, promyelocytic leukaemia (PML)/RAR $\alpha$ oncoprotein also inhibits caspase-independent PCD induced by the PML tumour-suppressor protein ${ }^{92}$. Interestingly, cytoplasmic apop totic features induced by ectopic expression of PML can even be enhanced by pan-caspase inhibitor ${ }^{92}$. It should, however, be noted that PML/RAR $\alpha$ is also thought to interfere with caspase activation in some death models ${ }^{93}$.

From theory to therapy. Although many cancer therapies induce classic apoptosis ${ }^{87}$, potential drugs engaging other death routines are emerging (FIG.3). For instance, the topoisomerase inhibitor camptothecin induces cathepsin D/B-mediated apoptosis-like PCD in hepatocellular carcinoma cells $s^{10}$; activation of a thrombospondin receptor (CD47) triggers programmed necrosis in B-cell chronic lymphoma cells ${ }^{33}$; interferons and arsenite initiate a caspase-independent death pathway, possibly mediated by PML ${ }^{92}$; and EB 1089 , a synthetic vitamin $D$ analogue, kills breast-cancer cells through a caspase-independent apoptosis-like $\mathrm{PCD}^{15}$ mediated by calpains (M.J., unpublished observations). Moreover, increased tumour cell death observed in vitro when combining stimuli that activate different deathinducing proteases indicates that therapies activating various $P C D$ pathways simultaneously might also be effective in the clinic ${ }^{94.95}$

Experimental gene-therapy approaches also point to alternative death pathways as promising targets for tumour therapy. For example, expression of Bin 1 or adenovirus protein E4orf4, as well as depletion of Hsp 70 , result in tumour-specific induction of caspaseindependent apoptosis-like $\mathrm{PCD}^{11.16,17.89}$.

\section{Alternative cell death in the nervous system}

Caspase-driven neuronal apoptosis strictly following the classic apoptosome pathway is best documented during development of the nervous system ${ }^{29}$, in which many superfluous cells are produced and turned over ${ }^{96}$, 


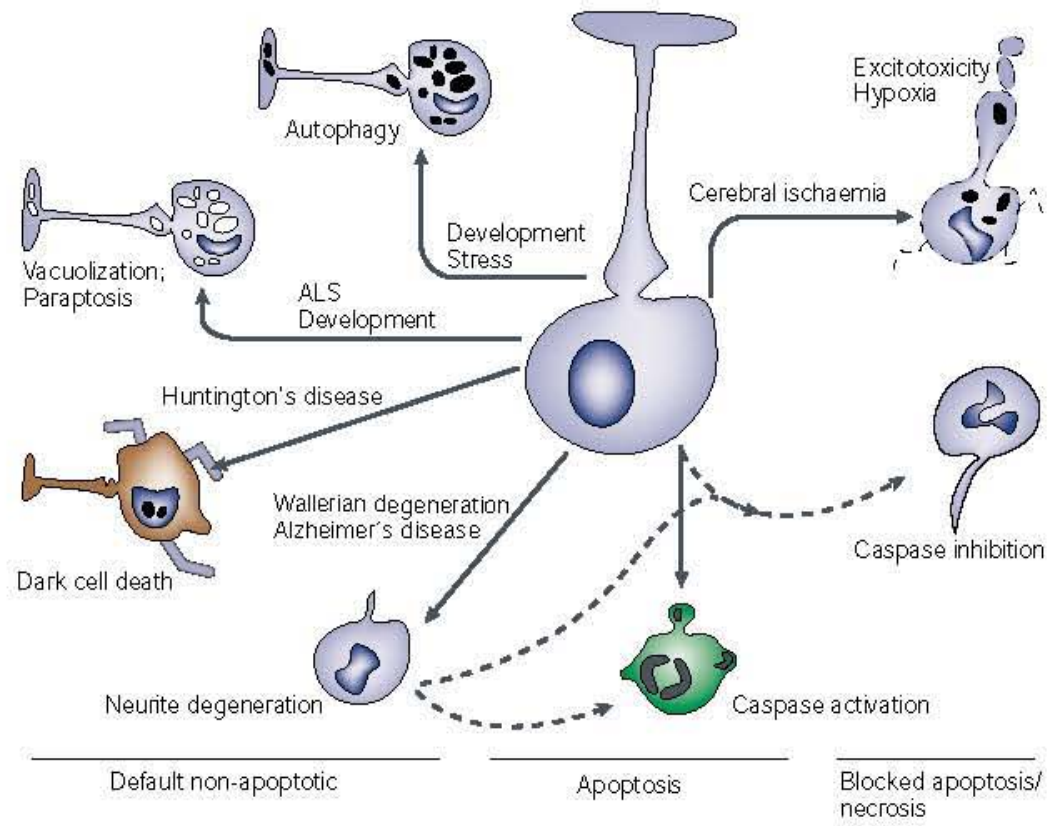

Figure 4 | Different modes of neuronal death. Developmental cell death occurs by caspasedependent apoptosis ${ }^{58}$ or morphologically and mechan istically distinct autophagy. In various human diseases or animal models of them, the dominant form of neuronal disease is, for example, dark cell death in a Huntington's disease mode ${ }^{40}$ or paraptosis in a model of amyotrophic lateral sclerosis $(A L S)^{104}$. Selective neurite degeneration occurs independently of caspase activation in different situations, and might eventually lead either to caspasedependent apoptosis of cell bodies or to non-apoptotic death with irregular chromatin condensation ${ }^{43.83}$. EXCITOTOXIC death may take many shapes and mechanisms, depending on the intensity of insult, the age of the animal and the region of the brain affected ${ }^{105.106}$. It often results in mixed apoptotic-necrotic features ${ }^{30}$, in cluding cellular swelling, blebbing, nuclear PYKNOSIs, display of phosphatidylserine and some autophagic processes, such as uptake of mitochondria into lysosomes.

PYKNOSIS

Poorly defined pathological term for nuclear condensation Mainly used to describe forms of non-apoptotic chromatin ondensation

EXCITOTOXICITY

Neuronal death triggered by overexcitation of ion channelgating (ionotropic) receptors (for example, ionotropic glutamate receptors). Release of endogenous excitotoxins triggers excitotoxic processes as common mechanism of neuronal loss during cerebral ischaemia. and in in vitrocultures of cells derived from developing brain ${ }^{58}$. Evidence is scarce for adult neurons, and here caspase-dependent mechanisms might yield to alternative death pathways ${ }^{97}$.

Cell suicide in the adult nervous system has serious implications for the whole organism, as turnover is classically limited. So a rapid caspase cascade, which is advantageous for efficient elimination of unwanted or rapidly replaceable cells, is dangerous in the developed brain and must be tightly controlled. For instance, neurons can survive cytochrome $c$ release from mitochondria, provided that they do not simultaneously receive a second signal leading to a 'competence to die ${ }^{98}$. Neuronally expressed apoptosis inhibitor proteins (IAP, NAIP) buffer the caspase system, and need to be inactivated before classic apoptosis can occur ${ }^{2}$. This buffering capacity might allow the localized activation of caspases ${ }^{58}$ (within synapses or neurites, for example) or the sequestration of active caspases ${ }^{99}$, without a build-up of the death cascade affecting the entire neuron. Stressed neurons might also acquire a temporary resistance, which allows them to withstand otherwise lethal insults - by excitotoxins, for example ${ }^{100}$. Such circumstances favour activation of slow, caspaseindependent elimination routines, in which damaged organelles are digested within a stressed cell, and the chance for rescue and reversibility is maintained until the process is complete ${ }^{101-103}$.
Although some caspase-dependent apoptosis might occur in the adult brain ${ }^{58}$, at least part of PCD in chronic neurodegenerative disease follows alternative mechanisms and results in different morphologies ${ }^{40,81.99102104-107}$ (FIG. 4). Further variation is observed in acute insults such as ischaemia or traumatic brain injury. In these cases, neurons within one brain region are exposed to different intensities of stress that trigger different death programmes. Some of the main excitotoxic processes, such as mitochondrial impairment and dissipation of cell membrane potential, differentially impair various secondary routines of $\mathrm{PCD}^{30,105,106}$. For instance, rapid ATP depletion or disturbance of the intracellular ion composition impair cytochrome $c$ induced caspase activation, and massive production of nitric oxide or calpain activation directly inactivate caspases ${ }^{30.51}$. Accordingly, cell death has mixed features of apoptosis and necrosis, and might rely on either caspases or calpains as the dominant execution proteases ${ }^{68}$, or the activation of $\mathrm{PARP}^{36}$ as a controller of programmed necrosis. Another group of proteases implicated as executors of ischaemic death are the cysteine cathep$\operatorname{sins}^{67}$. They might interact with calpains, and, notably, there is massive PCD in the brains of mice that lack the cathepsin inhibitor cystatin $\mathrm{B}^{108}$.

The special shape of neurons (with projections up to 40,000 times longer than their cell bodies) allows degradative processes to be localized to a part of neurons and different death processes to be activated in different subsections of the cell ${ }^{30.58}$. For instance, synaptic damage and neurite regression can occur by Bc1-2- and caspase-independent mechanisms ${ }^{43.83 .109}$, whereas final elimination of cells might depend on caspases or proteasomal activities ${ }^{43}$. The role of caspases as enhancers of the final phase of cell degeneration might apply to many common diseases. The longevity of neurons, combined with their dependence on effective intracellular transport, makes them sensitive to a slow form of death, associated with the formation of intracellular polypeptide aggregates irvolving the amyloid- $\beta$ precursor protein (APP), ataxins, presenilins, huntingtin, tau and $\alpha$-synuclein ${ }^{58}$. As most of these proteins are caspase targets ${ }^{110}$ and become more toxic after cleavage, caspases might contribute to the accelerated death of neurons at the end of a caspase-independent degeneration phase.

\section{Outlook}

The discovery and understanding of alternative death pathways will open new perspectives for the treatment of disease. On the one hand, the existence of caspaseindependent pathways provides new options to kill tumour cells (FIG. 3), with one of these therapies (vitamin $\mathrm{D}$ analogues) already having advanced into phase III clinical trials. On the other hand, combination of caspase-directed and alternative therapies provides a more efficient approach to circumvent the commonly observed therapy resistance of transformed cells ${ }^{94.95}$. New options and targets also emerge for the prevention of death processes in neurodegenerative disease. Prominent examples that have reached the stage of clini- 
HORIZONTAL TRANSFER Non-germline transmission of genetic material. cal trials target molecules such as PARP in necrosis or calpains in excitotoxicity $36,68,97$.

On a more general biological level, the mode of cell death might have differential effects on the surrounding tissue $^{56}$. The important roles of caspaseindependent/alternative death for development of tumour immunity are just emerging (reviewed in REF. 23). Most recent evidence shows that the mode of cell demise controls the HORIZONTAL spread of oncogenic information ${ }^{111}$ and infection ${ }^{112}$. As these processes can be favoured by caspase activation, the classic apoptosis pathways can, in fact, be detrimental to the organism. This might explain the need for extremely tight control of caspase activation by the cellular energy level ${ }^{19}$. The apparent paradox that death-bound ATP-depleted cells are not 'allowed' to activate caspases might then be explained by the fact that such cells would release activated caspases into the extracellular space upon premature lysis ${ }^{113}$. So non-apoptotic death might not only be a passive accident, but also, in some cases, be a desirable death option for long-lived organisms having to deal with tumours, infections and other non-lethal tissue insults throughout their lives.

\section{(D) Links}

DATABASE LINKS Bax | CED-9 | Bcl-2 | CED-3 poly(ADP) ribose polymerase $|\mathrm{CD} 2| \mathrm{TNF} \mid$ p21-activated kinase-2 | cathepsin D | cathepsin B TNFR1 | Fas |FADD | Daxx | ASK1 | JNK1 | Hsp27 | Bak $\mathrm{Bid}|\mathrm{Bim}| \mathrm{Bcl}-\mathbf{x}_{\mathrm{L}}|\mathrm{DIABLO} / \mathrm{Smac}|$ AIF $\mid$ CAD $\mid$ ORP150 Myc | E2F |CDC 25 | survivin | p53 | p19 arf $^{\text {aPML }}$ PAR $\alpha$ |CD47 | Bin1 | APP | ataxins | presenilins | huntingtin | tau $\mid \alpha$-synuclein $\mid$

FURTHER INFORMATION Cell Death Society | Jäättelä lab ENCYCLOPEDIA OF LIFE SCIENCES Apoptosis: molecular mechanisms |Apoptosis: morphological criteria and other assays
1. Kerr, J. F. R. Wyllie, A. H. \& Currie, A. R. Apoptosis: basic biological phenomenon with wide-ranging implications in tissue kinetics. Br. J. Cancer 26, 239-257 (1972)

2. Hengartner, M. O. The biochemistry of apoptosis. Nature 407, $770-776(2000)$.

3. Strasser, A., O'Connor, L. \& Dixit, V. M. Apoptosis signaling. Annu. Rev. Biochem. 69, 217-245 (2000).

4. Wright, S. C. et al. Activation of CPP32-like proteases is not sufficient to trigger apoptosis: inhibition of apoptosis by agents that suppress activation of AP24, but not CPP32like activity. J. Exp. Med. 186, 1107-1117 (1997).

5. Lacana, E., Ganjei, J. K.. Vito, P. \& D'Adamio, L. Dissociation of apoptosis and activation of IL-1 $\beta$ converting enzyme/Ced-3 proteases by ALG-2 and the truncated Alzheimer's gene ALG-3. J. Immunol. 158 5129-5135 (1997).

6. Jäättelä, M. Wissing, D., Kokholm, K., Kallunki, T. \& Egeblad. M. Hsp70 exerts its anti-apoptotic function downstream of caspase-3-like proteases. EMBO 17 6124-6134 (1998)

7. De Maria, R. et al. Negative regulation of erythropoiesis by caspase-mediated cleavage of GATA-1. Nature 401 489-493 (1999)

8. Harvey, K. J., Lukovic, D. \& Ucker, D. S. Caspase dependent $C d k$ activity is a requisite effector of apoptotic death events. J. Cell Biol. 148, 59-72 (2000)

9. Foghsgaard, L. et al. Cathepsin B acts as a dominan execution protease in tumor cell apoptosis induced by tumor necrosis factor. J. Cell Biol. 153, 999-1009 (2001). The first identification of a protease (cathepsin B) that mediates death-receptor-induced caspaseindependent apoptosis-like PCD. The requirement of cathepsin $B$ for phosphatidylserine exposure, cathepsin B for phosphatidylserine exposure, caspase-dependent death is also shown. Provides a table of specificity profiles for commonly used table of specificity prof
protease inhibitors.

10. Roberts, L. R.. Adjei, P. N. \& Gores, G. J. Cathepsins as effector proteases in hepatocyte apoptosis. Cell. Biochem. Biophys. 30, 71-88 (1999).

11. Lavoie, J. N., Nguyen, M.. Marcellus, R. C., Branton, P. E. \& Shore, G. C. E4orf4, a novel adenovirus death factor that induces $p 53$-independent apoptosis by a pathway that is not inhibited by zVAD-fmk. J. Cell Biol. 140, 637-645 (1998).

12. Berndt, C., Mopps, B., Angermuller, S., Gierschik, P. \& Krammer, P. H. CXCR4 and CD4 mediate a rapid CD95independent cell death in CD4+T cells. Proc. Natl Aca Sci. USA 95, 12556-12561 (1998).

13. Borner, C. \& Monney, L. Apoptosis without caspases: an inefficient molecular guillotine. Cell Death Differ. 6 . 497-507 (1999).

14. Kitanaka, C. \& Kuchino, Y. Caspase-independent programmed cell death with necrotic morphology. Cell Death Differ. 6. 508-515 (1999).

15. Mathiasen, I. S., Lademann, U. \& Jäättelä, M. Apoptosis induced by vitamin $D$ compounds in breast cancer cells is inhibited by $\mathrm{Bcl}-2$ but does not involve known caspases or p53. Cancer Res. 59, 4848-4856 (1999).

16. Nylandsted, J. et al. Selective depletion of heat shock protein 70 ( $\mathrm{Hsp} 70$ ) activates a tumor-specific death program that is independent of caspases and bypasses Bcl-2. Proc. NatlAcad. Sci. USA 97, 7871-7876 (2000). The first demonstration of an endogenous protein (Hsp70) that is specifically required for the survival of tumorigenic cells. The transformation-associated death programme inhibited by $\mathrm{Hsp} 70$ is shown to be caspase independent.

17. Elliott, K., Ge, K., Du, W. \& Prendergast, G. C. The c-Mycinteracting adaptor protein Bin1 activates a caspaseindependent cell death program. Oncogene 19 4669-4684 (2000)

18. Joza, N. et al. Essential role of the mitochondria apoptosis-inducing factor in programmed cell death. Nature 410, 549-554 (2001). Gene deletion of Aif in mice. Genetic evidence for the essential role of AIF in developmental apoptosis.

19. Leist, M., Single, B., Castoldi, A. F. Kuhnle, S. \& Nicotera, P. Intracellular adenosine triphosphate (ATP) concentration a switch in the decision between apoptosis and necrosis. a switch in the decision between apoptos
J. Exp. Med. 185, 1481-1486 (1997)

Initial demonstration that initially similar cell-death Initial demonstration that initially similar cell-deat
signals are switched between apoptosis and signals are switched between apoptosis and
programmed necrosis by metabolic conditions in the program.

20. Vercammen, D. et al. Dual signaling of the Fas receptor: initiation of both apoptotic and necrotic cell death pathways. J. Exp. Med. 188, 919-930 (1998). Demonstrates the ability of tumour necrosis factor receptor 1 and Fas to trigger caspase-independent programmed necrosis, mediated by the production of mitochondrial reactive oxygen species.

21. Leist. M. et al. Inhibition of mitochondrial ATP generation Leist, M. et al. Inhibition of mitochondrial ATP generation
by nitric oxide switches apoptosis to necrosis. Exp. Cell Res. 249, 396-403 (1999)

22. Chung, S., Gumienny, T. L. Hengartner, M, O. \& Driscoll, M A common set of engulfment genes mediates removal of both apoptotic and necrotic cell corpses in C. elegans. Nature Cell Biol. 2. 931-937 (2000)

23. Hirt, U. A., Gantner, F. \& Leist, M. Phagocytosis of nonapoptotic cells dying by caspase-independent mechanisms. J. Immunol. 164, 6520-6529 (2000). Shows that cells dying by different caspaseindependent mechanisms can be recognized by phagocytes in various ways and can be efficiently ingested.

24. Aravind, L., Dixit, V. M. \& Koonin, E. V. Apoptotic molecular machinery: vastly increased complexity in vertebrates revealed by genome comparisons. Science 291 1279-1284 (2001)

25. Frohlich. K. U. \& Madeo, F. Apoptosis in yeast - a monocellular organism exhibits altruistic behaviour. FEBS Lett. 473, 6-9(2000).

26. Ameisen, J.C. The origin of programmed cell death. Science 272, 1278-1279 (1996).
27. Wyllie, A. H. \& Golstein. P. More than one way to go, Proc NattAcad. Sci. USA 98, 11-13 (2001)

28. Ellis. H. M. \& Honvitz, H. R. Genetic control of programmed cell death in nematode $C$. elegans. Cell 44, 817-829 (1986)

29. Los, M., Wesselborg, S. \& Schulze-Osthoff, K. The role of caspases in development, immunity, and apoptotic signal transduction: lessons from knockout mice. immunity 10. 629-639 (1999).

30. Nicotera, P., Leist, M. \& Manzo, L. Neuronal cell death: a demise with different shapes. Trends Pharmacol. Sci, 20 46-51 (1999).

31. Woodle. E. S. et al. Anti-human class I MHC antibodies induce apoptosis by a pathway that is distinct from the Fas antigen-mediated pathway. J. Immunol. 158, 2156-2164 (1997)

32. McCarthy, N. J., Whyte, M. K. B., Gilbert, C. S. \& Evan, G. I. Inhibition of Ced-3//CE-related proteases does not prevent cell death induced by oncogenes. DNA damage, or the Bcl-2 homologue Bak. J. Cell Biol. 136, 215-227 (1997). Shows that caspase activation functions as a general switch between necrosis and apoptosis, but is not required for death itself.

33. Mateo, $V$ et $a l . C D 47$ ligation induces caspaseindependent cell death in chronic lymphocytic leukemia. Nature Med. 5. 1277-1284 (1999).

34. Holler, N. et al. Fas triggers an alternative, caspase-8independent cell death pathway using the kinase RIP as effector molecule. Nature immunol. 1, 489-495 (2000). The first description of the requirement of RIP kinase activity for the death-receptor-induced necrotic pathway. Also indicates that programmed necrosis might be the dominant death mode induced by Fas in activated primary lymphocytes.

35. Schulze-Osthoff, K. et al. Cytotoxic activity of tumor necrosis factor is mediated by early damage of mitochondrial functions. Evidence for the involvement of mitochondrial radical generation. J. Biol. Chem. 267. $5317-5323$ (1992)

36. Ha, H. C. \& Snyder, S. H. Poly(ADP-ribose) polymerase is a mediator of necrotic cell death by ATP depletion. Proc. Natl Acad. Sci. USA 96. 13978-13982 (1999).

37. Bursch, W. et al. Active cell death induced by the antiestrogens tamoxifen and ICl 164384 in human mammary carcinoma cells (MCF-7) in culture: the role of autophagy. Carcinogenesis 17, 1595-1607 (1996)

38. Chi, S. et al, Oncogenic Ras triggers cell suicide through the activation of a caspase-independent cell death program in human cancer cells. Oncogene 18, 2281-2290 (1999)

39. Roach, H. I. \& Clarke, N. M. Physiological cell death of chondrocytes in wivo is not confined to apoptosis. New observations on the mammalian growth plate. J. Bone Joint Surg. Br. 82, 601-613 (2000)

40. Turmaine, M. et al. Nonapoptotic neurodegeneration in a transgenic mouse model of Huntington's disease. Proc. Natl Acad. Sci. USA 97, 8093-8097 (2000).

41. Deas, 0 . et al. Caspase-independent cell death induced 
by anti-CD2 or staurosporine in activated human peripheral T lymphocytes. J. Immunol. 161, 3375-3383 (1998).

42. Luschen S. Ussat, S., Scherer, G., Kabelitz, D. \& AdamKlages, S. Sensitization to death receptor cytotoxicity by inhibition of $\mathrm{FADD} / \mathrm{caspase}$ signaling: requirement of cell inhibition of $\mathrm{FADD} / \mathrm{caspase}$ signaling: requirement of (2000).

43. Volbracht, C., Leist, M., Kolb, S. A. \& Nicotera, P. Apoptosis in caspase-inhibited neurons. Mol. Med. 7. 36-48 (2001).

44. Xue, L., Fletcher, G. C. \& Tolkorsky, A, M. Autophagy is activated by apoptotic signalling in sympathetic neurons: an alternative mechanism of death execution. Mol Cell Neurosci. 14. 180-198 (1999)

45. Xiang, J., Chao, D. T. \& Korsmeyer, S. J. Bax-induced cell death may not require interleukin $1 \beta$-converting enzymelike proteases. Proc. Natl Acad. So USA 93 145e proteases. Proc. Nat The first demonstration of caspase-independent programmed cell death induced by Bax-like molecules.

46. Khwaja, A. \& Tatton, L. Resistance to the cytotoxic effects of tumor necrosis factor- $\alpha$ can be overcome by inhibition of a FADD/caspase-dependent signaling pathway. J. Biol. Chem. 274, 36817-36823 (1999).

47. Chautan, M. Chazal, G Cecconi, F Gruss, P. \& Golstein. P. Interdigital cell death can occur through a necrotic and caspase-independent pathway. Curr. Biol. 9, 967-970 (1999)

48. Matsumura, H. et al: Necrotic death pathway in Fas receptor signaling. J. Cell Biol. 151, 1247-1256 (2000).

49. Amarante-Mendes, G. P. et al, Anti-apoptotic oncogenes prevent caspase-dependent and independent commitment for cell death. Cell Death Differ. 5, 298-306 (1998).

50. Chua, B. T., Guo, K. \& Li. P. Direct cleavage by the calcium-activated protease calpain can lead to inactivation of caspases. J. Biol. Chem. 275, 5131-5135 (2000).

51. Lankiewicz, S. et al. Activation of calpain I converts excitotoxic neuron death into a caspase-independent cell death. J. Biol. Chem. 275, 17064-17071 (2000).

52. Jäăttelä, M. Escaping cell death: survival proteins in cancer. Exp. Cell Res. 248, 30-43 (1999)

53. Smith, K. G., Strasser, A. \& Vaux, D. L. CrmA expression in Tlymphocytes of transgenic mice inhibits CD95 (Fas/ APO-1)-transduced apoptosis, but does not cause lymphadenopathy or autoimmune disease. EMBO J.15, 5167-5176 (1996).

54. Doerfler, P., Forbush, K. A. \& Perlmutter, R. M. Caspase enzyme activity is not essential for apoptosis during thymocyte development. J. immunol. 164, 4071-4079 (2000).

55. Kunstle, G. et ol. Concanavalin A hepatotoxicity in mice: tumor necrosis factor-mediated organ failure independen of caspase-3-like protease activation. Hepatology 30 1241-1251 (1999).

56. Savill, J. \& Fadok. V. Corpse clearance defines the meaning of cell death. Nature 407, 784-788 (2000).

57. Wolf, B. B. et al. Calpain functions in a caspaseindependent manner to promote apoptosis-like events during platelet activation. Blood 94, 1683-1692 (1999).

58. Mattson. M. P. Apoptosis in neurodegenerative disorders Nature Rev. Mol. Cell Biol. 1. 120-129 (2000).

59. Leverrier, Y. \& Ridley, A. J. Apoptosis: caspases orchestrate the ROCK ' $n$ ' bleb. Nature Cell Biol. 3. E91-E93 (2001)

60. Deiss, L. P., Galinka, H., Berissi, H., Cohen, O. \& Kimchi, A. Catepsin D protease mediates programmed cell death induced by interferon- $\gamma$. Fas/APO- 1 and TNF- $\alpha$. EMBO J. 15. 3861-3870(1996)

61. Guicciardi, M. E. et al. Cathepsin B contributes to TNF- $\alpha$ mediated hepatocyte apoptosis by promoting mitochondrial release of cytochrome $c$. J. Clin. Invest. 106 $1127-1137(2000)$.

62. Waterhouse, N. J. et al. Calpain activation is upstream of caspases in radiation-induced apoptosis. Cell Death Differ 5. 1051-1061 (1998)

63. Vanags, D. M. Porn-Ares, M. I. Coppola, S., Burgess. D. H. \& Orrenius, S. Protease involvement in fodrin cleavage and phosphatidylserine exposure in apoptosis. $J$. Biol. Chem. 271, 31075-31085 (1996)

64. Johnson. D. E. Noncaspase proteases in apoptosis. Leukemia 14. 1695-1703 (2000).

A review that profoundly discusses different proteases and the technologies used to identify their contribution to cell death.

65. Leist, M. \& Jäättelä, M. Triggering of apoptosis by cathepsins. Cell Death Differ. 8, 324-326 (2001).

66. Squier, M. K., Miller, A. C.. Malkinson, A. M. \& Cohen, J. J.
Calpain activation in apoptosis. J. Cell Physiol. 159. 229-237 (1994)

67. Yamashima, T. Implication of cysteine proteases calpain cathepsin and caspase in ischemic neuronal death of primates. Prog. Neurobiol, 62, 273-295 (2000).

68. Wang $K . K$. Calpain and caspase: can you tell the difference? Trends Neurosci. 23, 20-26 (2000).

69. Roberg, K. Relocalization of cathepsin D and cytochrome $c$ early in apoptosis revealed by immunoelectron microscopy. Lab. invest. 81, 149-158 (2001).

70. Schotte, P., Declercq, W. Van Huffel, S., Vandenabeele, P. \& Beyaert, R. Non-specific effects of methyl ketone peptide inhibitors of caspases. FEBS Lett. 442, 117-121 (1999).

71. Laster, S. M., Wood, J. G. \& Gooding, L. R. Tumor necrosis factor can induce both apoptic and necrotic forms of fol cin

72. Kawahara, A. Onsawa, Y.. Matsumura, H., Uchiyama, Y. \& Nagata, S. Caspase-independent cell killing by Fasassociated protein with death domain. J. Cell Biol. 143. $1353-1360(1998)$

73. Yang, X. Koshravi-Far, R., Chang, H. Y. \& Baltimore, D. Daxx, a novel Fas-binding protein that activates JNK and apoptosis. Cell 89, 1067-1076 (1997)

74. Chang, H. Y., Nishitoh, H.. Yang, X., Ichijo, H. \& Baltimore, D. Activation of apoptosis signal-regulating kinase 1 (ASK1) by the adapter protein Daxx. Science 181, 1860-1863 (1998).

75. Tobiume, K. et al. ASK 1 is required for sustained activations of JNK/p38 MAP kinases and apoptosis. EMBO Rep. 2, 222-228 (2001)

76. Tournier, C. et $a$ I. Requirement of JNK for stress-induced activation of the cytochrome $c$-mediated death pathway. Science 288, 870-874 (2000)

77. Charette, S. J., Lavoie, J. N., Lambert, H. \& Landry, J. Inhibition of Daxx-mediated apoptosis by heat shock protein 27. Mol. Cell. Biol. 20, 7602-7612(2000)

78. Susin, S. A. et al Molecular characterization of mitochondrial apoptosis-inducing factor. Nature 397 mitochondrial ap

\section{Cloning and cell biological characterization of the} mitochondrial caspase-independent programmed cell death mediator AIF.

79. Suter, M. et al. Age-related macular degeneration. The lipofusion component $\mathrm{N}$-retinyl- $\mathrm{N}$-retinylidene ethanolamine detaches proapoptotic proteins from mitochondria and induces apoptosis in mammalian retinal pigment epithelial cells, J. Biol. Chem. 275, 39625-39630 (2000).

80. Daugas, E. et al. Mitochondrio-nuclear translocation of AIF in apoptosis and necrosis. FASEB J, 14, 729-739 (2000)

81. Miller. TM et al. Bax deletion further orders the cell death pathway in cerebellar granule cells and suggests a caspase-independent pathway to cell death. J. Cell Biol 139. 205-217 (1997)

82. Hirsch, T, et $a !$. The apoptosis-necrosis paradox Apoptogenic proteases activated after mitochondrial permeability transition determine the mode of cell death Oncogene 15, 1573-1581 (1997).

83. Finn, J. T. et al. Evidence that Wallerian degeneration and localized axon degeneration induced by local neurotrophin deprivation do not involve caspases. J. Neurosci. 20 $1333-1341(2000)$

84. Schierle, G. S. et al! Differential effects of $\mathrm{Bcl}-2$ overexpression on fibre outgrowth and sunvival of embryonic dopaminergic neurons in intracerebra transplants. Eur. J. Neurosci. 11, 3073-3081 (1999).

85. Tamatani, M. et al. ORP150 protects against hypoxia/ischemia-induced neuronal death. Nature Med. 7 317-323 (2001)

86. Schmitt, C. A. \& Lowe, S. W. Apoptosis and therapy. J. Pathol. 187, 127-137 (1999)

87. Kerr, J. F. R., Winterford, C. M. \& Harmon, B. V. Apoptosis. Its significance in cancer and cancer therapy. Cancer 73 . 2013-2026 (1994)

88. Lavoie, J. N. Champagne, C.. Gingras, M. C. \& Robert, A. Adenovirus $\mathrm{E} 4$ open reading frame 4 -induced apoptosis involves dysregulation of Sic family kinases. J. Cell Biol. 150. $1037-1056(2000)$

89. Nylandsted, J., Brand, K. \& Jäattelä, M. Heat shock protein 70 is required for the survival of cancer cells. Ann. NY Acad. Sci. 926, 122-125 (2000).

90. Duffy, M. J. Proteases as prognostic markers in cancer. Clin. Cancer Res. 2, 613-618 (1996)

91. Alexander, C. M., Howard, E. W. Bissell, M. J. \& Werb, Z. Rescue of mammary epithelial cell apoptosis and entactin degradation by a tissue inhibitor of metalloproteinases-1 transgene. J. Cell Biol. 135, 1669-1677 (1996).

92. Quignon, F. et al. PML induces a novel caspase independent death process. Nature Genet. 20, 259-265
(1998)

The first demonstration of a tumour-suppresso protein (PML) that activates a caspase-independent PCD.

93. Wang, Z. G, et al. PML is essential for multiple apoptotic pathways. Nature Genet. 20, 266-272 (1998).

94. Wang, Q. Yang, W. Uytingco, M. S. Christakos, S. \& Wieder, R. 1,25-Dihydroxyvitamin D3 and all-trans-retinoic acid sensitize breast cancer cells to chemotherapyinduced cell death. Cancer Res, 60, 2040-2048 (2000).
Mathiasen, I. S.. Hansen. C. M., Foghsgaard, L. \& Jäättelä, M. Sensitization to TNF-induced apoptosis by 1,25 dihydroxy vitamin $D(3)$ involves up-regulation of the TNF receptor 1 and cathepsin B. Int. J. Cancer 93, 224-231 (2001).

96. Raff. M. C. Social controls on cell survival and cell death. Nature 356, 397-400 (1992)

97. Johnson, M. D. Kinoshita, Y. Xiang, H. Ghatan, S. \& Morrison, R. S. Contribution of p 53 -dependent caspase activation to neuronal cell death declines with neuronal maturation. J. Neurosci. 19, 2996-3006 (1999)

98. Deshmukh. M. Kuida, K. \& Johnson. E. M. Jr Caspase inhibition extends the commitment to neuronal death beyond cytochrome crelease to the point of mitochondrial depolarization. J. Cell Biol. 150, 131-143 (2000).

99. Stadelmann, C, et al. Activation of caspase- 3 in single neurons and autophagic granules of granulovacuolar degeneration in Alzheimer's disease. Evidence for apoptotic cell death. Am. J. Pathol. 155, 1459-1466 (1999).

100. Hansson, O. et al. Transgenic mice expressing a Huntington's disease mutation are resistant to quinolinic acid-induced striatal excitotoxicity. Proc. Natl Acad. Sc USA 96, 8727-8732 (1999)

101. Yamamoto, A., Lucas, J. J.\& Hen, R. Reversal of neuropathology and motor dysfunction in a conditional model of Huntington's disease. Cell 101, 57-66 (2000).

102. Jellinger, K. A. \& Stadelmann, C. H. The enigma of cell death in neurodegenerative disorders 3 Neural Transm. S21-S36 (2000)

103. Xue, L., Fletcher, G. C. \& Tolkovsky, A. M. Mitochondria are selectively eliminated from eukaryotic cells after blockade of caspases during apoptosis. Curr. Biol. 11. 361-365 (2001)

104. Sperandio, S., de Belle, I. \& Bredesen, D. E. An alternative, nonapoptotic form of programmed cell death. Proc. Natl Acad. Sci. USA 97, 14376-14381 (2000). Definition of paraptosis as a mode of neuronal death that is independent of caspase activity. Contains numerous ref erences on alternative death modes.

105. Fujikawa, D. G. Confusion between neuronal apoptosis and activation of programmed cell death mechanisms in acute necrotic insults. Trends Neurosci. 23, 410-411 (2000)

106. Roy, M. \& Sapolsky. R. Neuronal apoptosis in acute necrotic insults: why is this subject such a mess? Trends Neurosci. 22, 419-422 (1999).

107. Colbourne, F., Sutherland, G. R. \& Auer, R. N. Electron microscopic evidence against apoptosis as the mechanism of neuronal death in global ischemia. J. Neurosci. 19, 4200-4210 (1999).

108. Pennacchio, L. A. et al. Progressive ataxia, myoclonic epilepsy and cerebellar apoptosis in cystatin B-deficient mice. Nature Genet. 20, 251-258 (1998).

109. Sagot, Y. et al. Bcl-2 overexpression prevents motoneuron cell body loss but not axonal degeneration in a mouse model of a neurodegenerative disease. J. Neurosci. 15 7727-7733 (1995).

110. Wellington. C. L. \& Hayden, M. R. Caspases and neurodegeneration: on the cutting edge of new therapeutic approaches. Clin. Genet. 57, 1-10 (2000).

111. Bergsmedh. A. et al. Horizontal transfer of oncogenes by uptake of apoptotic bodies. Proc. Nat/ Acad. Sci. USA 98 6407-6411 (2001).

112. Boise, L. H. \& Collins, C. M. Salmonella-induced cell death: apoptosis, necrosis or programmed cell death? Trends Microbiol. 9. 64-67 (2001).

113. Hentze, $H$. et al in vivo and in vitro evidence for extracellular caspase activity released from apoptotic cells. Biochem. Biophys. Res. Commun. 283, 1111-1117 (2001).

114. Torriglia, A. et al. A caspase-independent cell clearance

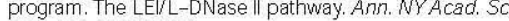
926, 192-203 (2000).

Acknowledgements

We acknowledge our colleagues for stimulating discussions and the Danish Cancer Society, the German Research Council and the Danish Medical Research Council for financial support. We also apologize to those whose work could only be cited indirectly. 